\title{
Antimicrobial Use for The Food Production Animals: Needs \& Harms
}

\author{
Mohamed Ali Alhosani* \\ Veterinary Laboratories Division, Animal Health Sector, Abu Dhabi Agriculture and Food Safety Authority (ADAFSA), Abu Dhabi, UAE
}

*Corresponding author: Mohamed Ali Alhosani. Animal Health Sector, Abu Dhabi Agriculture and Food Safety Authority (ADAFSA), Abu Dhabi, UAE.

Received Date: December 08, 2019

Published Date: December 11, 2019

\section{Opinion}

Since centuries, the human is depending on the farm animals as a source of food, commerce, transport, and others, a thing that develop the caring practice of the humans toward the animals to keep them safe and healthy. And with the progress of the time and existing of the alternate sources, the purpose of having the farm animals is changed to be either for fun or wealth. And for those who have the interest to use the farm animals as commercial source, they are facing several challenges to maintain the health and life quality of the animals. therefore, many of the animal owners are biased to use the antimicrobial drugs as a quick and affordable tool to promote the growth and protect the animals from microbial infections. And this evidenced by several documents reported that most of the antimicrobial drugs administrated for food-producing animals are used as growth promoter, prophylaxis and metaphylaxis [1].

As good as using the antimicrobial as protecting agents, it can harm the animal and human health when it abused. Overdosing of these drugs is enhancing the microorganisms to protect themselves through several mechanisms such as acquiring and expressing resistant genes against the administrated antimicrobial drugs, and possible other antimicrobial drugs as well, and sharing these genes with other bacteria [2]. The resistant microorganisms and especially resistant bacteria could be considered as "contagion" if it grows in a poor environment that rich by facilitating factors such as poor housing, weak infection control management, limited cleaning and disinfecting of the environment [3]. Moreover, most of the bacteria can be transmitted within and between animals, humans, and environment as well as the resistant genes, and most of the antimicrobial drugs classes are common between the human and animals, a thing that reflect the high risk of abusing these drugs on the human health. There are several evidences showed that the antimicrobial resistance of some pathogens such as Salmonella spp. and Escherichia coli (E. coli) which isolated from humans are contributed to antimicrobial drugs used in animals.

As an example, Non-typhoidal Salmonella (NTS) is one of the common foodborne bacteria that primarily cause gastroenteritis, bacteremia, and focal infection in human [4]. This bacterium is hosted by several animals such as poultry, pigs, and cattle; and in pets, including cats, dogs, birds, and reptiles such as turtles [5]. It has been shown that the isolated antimicrobial resistant Salmonella from meat and poultry products are due to the contamination with the feces of the carrier animals [6]. In addition, some of the isolated NTS from human showed antimicrobial resistance against the third generation cephalosporins antibiotics, which can be contributed to the mass using of this antibiotic as a therapy or prophylaxis in animals and poultries [7].

Another example is using colistin antibiotic as a growth promoter. Colistin is an antimicrobial drug used since decades to treat both human and animal. And this drug has been approved by several countries to be used as growth promoter, a thing that led most of the animal breeders to use it to improve their animal fatten with ignorance of the side effect or negative impacts of this drug. And as consequence, antimicrobial resistance against colistin showed by E. coli which is isolated from livestock [8-9]. Moreover, mobile colistin-resistance gene (MCR-1) was identified in E. coli which isolated from food producing animals in several countries [10-11]. On the other hand, for the human colistin is considered as one of the last-resort antibiotics to treat infections caused by multidrugresistant Gram-negative bacteria such as Enterobacteriaceae and Pseudomonas aeruginosa in human [12].

In conclusion, using antimicrobial drugs for food producing animals is a double-edged sword, as good as it is a health protector and growth promoter, as bad as it can develop several negative impacts on animals, humans, and environment. 


\section{Acknowledgment}

None.

\section{Conflicts of Interest}

No conflicts of Interest.

\section{References}

1. Boeckel TP, Brower C, Gilbert M, Grenfell BT, Levin SA, et al. (2015) Global Trends in Antimicrobial Use in Food Animals. Proc. Natl. Acad. Sci. USA 112: 5649-5654.

2. Holmes AH, Moore LSP, Sundsfjord A, Steinbakk M, Regmi S, et al. (2016) Understanding the Mechanisms and Drivers of Antimicrobial Resistance. Lancet 387: 176-187.

3. Bürgmann H, Frigon D, Gaze WH, Manaia CM, Pruden A, et al. (2018) Water and Sanitation: An Essential Battlefront in the War on Antimicrobial Resistance. FEMS Microbiol. Ecol 94(9).

4. Hohmann EL (2001) Nontyphoidal Salmonellosis. Clin Infect Dis 32(2): 263-269.

5. World Health Organization (2018) Salmonella (non-typhoidal) (Fact Sheet). Retrieved from https://www.who.int/news-room/fact-sheets/ detail/salmonella-(non-typhoidal).

6. Food and Agriculture Organization (FAO), World Organization for Animal Health (OIE), World Health Organization (WHO). (2003) Joint
FAO/OIE/WHO Expert Workshop on Non-Human Antimicrobial Usage and Antimicrobial Resistance: Scientific Assessment. WHO: Geneva, Switzerland?

7. Collignon PJ, McEwen SA (2019) One Health-Its Importance in Helping to Better Control Antimicrobial Resistance. Trop Med Infect Dis. 4(1): E22.

8. Bennett PM, Enne VI, Cassar C, Sprigings K, Woodward MJ. (2008) A high prevalence of antimicrobial resistant Escherichia coli isolated from pigs and a low prevalence of antimicrobial resistant E. coli from cattle and sheep in Great Britain at slaughter. FEMS Microbiol Lett. 278: 193-199.

9. Lu L, Dai L, Wang Y, Wu C, Chen X, et al. (2010) Characterization of antimicrobial resistance and integrons among Escherichia coli isolated from animal farms in eastern China. Acta Trop. 113(1): 20-25.

10. Liu YY, Wang Y, Walsh TR, Yi LX, Zhang R, et al. (2016) Emergence of plasmid-mediated colistin resistance mechanism MCR-1 in animals and human beings in China: a microbiological and molecular biological study. Lancet Infect Dis 16(2): 161-168.

11. Walsh TR, Wu Y (2016) China bans colistin as a feed additive for animals. Lancet Infect Dis. 16(10): 1102-1103.

12. Rhouma M, Beaudry F, Letellier A (2016) Resistance to colistin: what is the fate for this antibiotic in pig production?. Int J Antimicrob Agents. 48(2): 119-126 